\title{
METAFICCIÓN E IRONÍA VERBAL EN EL MÓN D'HORACI, DE VICENÇ PAGÈS JORDÀ ${ }^{1}$
}

\author{
Moisés Llopis i Alarcon \\ Pontificia Universidad Católica de Chile \\ Universidad de Chile \\ moisesllopis@gmail.com
}

\begin{abstract}
RESUMEN/ ABSTRACT
El artículo analiza las diferentes modalidades de ironía presentes en El món d'Horaci (2016 [1995]), la primera novela de Vicenç Pagès Jordà: las reflexiones metaficcionales a cargo de los narradores y de los personajes, y las ironías verbales. El análisis muestra la diversidad de las ironías presentes en El món d'Horaci, base de la reflexión y la exploración del recurso en la obra posterior del autor.
\end{abstract}

Palabras Clave: ironía verbal, metaficción, literatura catalana, Vicenç Pagès Jordà, El món d'Horaci.

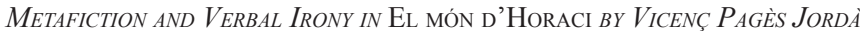

This paper analyses the different types of irony present in El món d'Horaci (2016 [1995]), Vicenç Pagès Jordà's first novel. These include meta-fictional reflections by narrators and characters and verbal ironies. The analysis shows the diversity of ironies present in El món d'Horaci, the basis of the reflection and the exploration of irony in the subsequent production of the author.

$1 \quad$ El Grup de Literatura Catalana Contemporània de la Universitat de València ha dedicado los últimos años a estudiar la presencia de la ironía (textual, paratextual, intertextual y metatextual) en la literatura catalana (Carbó et al. 2008 y 2011; Carbó, Gregori y Rosselló 2016). El investigador interesado puede consultar en línea la base de datos bibliográficos del grupo de investigación sobre estudios de ironía, parodia y pastiche en la literatura catalana desde el inicio del siglo xx hasta la actualidad en la dirección: http://www.uv.es/ironialitcat. 
KEYWORDS: verbal irony, metafiction, catalan literature, Vicenç Pagès Jordà, El món d'Horaci.

Recepción: 19/04/2017

Aprobación: 16/06/2017

\section{EL MÓN D'HORACI Y LA IRONÍA DE VICENÇ PAGÈS JORDÀ}

En 2016 se reeditó El món d'Horaci, la primera novela de Vicenç Pagès Jordà, publicada originalmente en 1995. Sin embargo, como aclara el autor en el epílogo que cierra la obra, "Vint-i-un anys després",

seria incorrecte afirmar que l'he reescrit [...]. He mantingut tots els capítols, però he eliminat alguna frase que ara trobo sobrera o que m’ha produït una vergonya gairebé aliena, algun paràgraf de la lliçó del professor Deulofeu, i alguna nota a peu de pàgina a la qual ara no acabava de trobar sentit (les notes, per cert, no han estat actualitzades, ja que corresponen a un anotador dels anys noranta). En canvi he afegit algun aclariment, i sobretot aquest epíleg, que ocupa si fa no fa el mateix espai que els fragments suprimits $(397)^{2}$.

La ocasión sirve al autor, además, para otorgar a la novela el protagonismo que no tuvo en el momento de la publicación, ya que "no va esgotar cap edició, no va guanyar cap premi, no s'ha traduït a cap llengua, no ha estat comentat en cap club de lectura, i ha tardat més de vint anys a reeditar-se" (389). Previamente, en el año 1990, Pagès Jordà había publicado un libro de cuentos, Cercles d'infinites combinacions, con una acogida excelente y una opinión crítica favorable. Sin embargo, El món d'Horaci no gozó de la misma unanimidad. A pesar de algunas opiniones desfavorables, Julià Guillamon, en una crítica publicada en La Vanguardia, afirmaba que "es la novela de alguien que cree en la literatura, que recurre a homenajes, referencias textuales, juegos eruditos. [...] Es un libro en el que se ha invertido un gran esfuerzo en más de una dirección" (Guillamon 34). Ponç Puigdevall, en El Punt del 20 de enero de 1996, puntualizaba que "Vicenç Pagès ha escollit a l'hora d'escriure la seva primera novel'la l'exploració i aprofundiment sistemàtic de la zona més arriscada" (Puigdevall, "Els perseguidors" s.p.); una opinión que se vio

2 Todas las citaciones de El món d'Horaci corresponden a la edición de 2016, cuya referencia completa aparece en la bibliografía final. A lo largo del artíiculo, solo consignaremos las páginas entre paréntesis. 
reforzada con la reimpresión cuando afirmó que estamos delante de un "llibre titànic" (Puigdevall, "Epílegs que insinuen" s.p.). Sara Serrano Valenzuela define El món d'Horaci como una "novel·la experimental, a cavall entre la ficció i l'assaig creatiu". Andreu Ayats, en su ensayo L'aventura de narrar. L'ofici de narrador i els seus moments inefables (73) dice de la novela de Pagès que "potser sense pretendre-ho, esdevé un llibre utilíssim per a un aprenent de narrador" porque "mostra suggerentment com s'escriu un text narratiu" y repasa los aspectos esenciales: la construcción de un argot particular, los límites del ensayo y la literatura, la frontera ficción/realidad, la exploración de voces narrativas o el juego de lectura a través del aparato de notas.

En general, la bibliografía dedicada a esta primera novela (y también al resto de su obra narrativa) ha destacado la ironía y el humor como elementos esenciales, pero sin llegar a un acuerdo en el alcance ni en el carácter de estos conceptos tan disímiles. Por ejemplo, Ponç Puigdevall apunta que "Vicenç Pagès ha triat per conjugar l'humor amb la conxorxa mediàtica i la simultaneïtat de la vida global del planeta" (s.p.). Enric Sullà, encargado del texto que cierra la reimpressión de la novela, apunta que El món d'Horaci "conrea, amb molta ironia, el joc literari i intertextual, els focs d'artifici estilístics" (Sullà 405). De una manera más general, Màrius Serra (s.p.) destaca los "mecanismes enigmístics" presentes en la novela y puestos "al servei del fals": el encadenado y el lipograma. Sin embargo, con los objetivos de alcanzar una claridad conceptual y un rigor metodológico, es imprescindible diferenciar la ironía de otros conceptos problemáticos, como la comicidad o el humor. En efecto, como señala Schoentjes (222-223), "l'ironie est un phénomène plus intellectuel" asociado a una reflexión y a unos mecanismos de funcionamiento racionales mientras que el humor (o la comicidad) está vinculado a los sentidos y a los sentimientos, dejando en suspenso la razón. En este mismo punto, el estudioso francés, como también lo han hecho anteriormente D.C. Muecke (36) o Pere Ballart (442), señala la otra característica definitoria de la ironía: "est un mode indirect et dissimulateur", es decir, la ironía permite una distancia entre el ironista y lo que dice. Dentro de este concepto de ironía podemos incluir, en efecto, "procedimientos retóricos, ficcionalización de su propia persona, dramatización de la acción, etc.” (Ballart 319).

Otros elementos destacados por la crítica han sido el papel del narrador y la multiplicidad de formas narrativas. En este sentido, Pere Antoni Pons (47) define la novela como "un món de possibilitats narratives i d'estratègies formals", que motiva, entre otros, "un vertigen de paranoies lúdiques i pertorbades" con una "prosa segura, precisa i divertida". Jordi 
Marrugat, en su ensayo Narrativa catalana de la postmodernitat, describe El món d'Horaci en términos d'"un calidoscopi compost de veus i gèneres narratius diversos que atenyen la unitat a partir de la diferència" (119) y, más adelante, como un "collage de referents culturals espectaculars (240). En efecto, El món d'Horaci se estructura a partir de un conjunto de narraciones yuxtapuestas recogidas bajo el nombre de "Els arxius de Lísia" en los que diferentes narradores extradiegéticos desarrollan el argumento de la novela. En ocasiones, el narrador de cada una de estas narraciones se asocia a la voz de alguno de los personajes, en cuyo caso hablaríamos de un narrador extra-homodiegético: (BIQUIBER [Berto], COSYMB [Ymbert], HORAHEL [Horaci y Helga], Xerrimax [Xerri y Max], Blochor1-4 [Horaci], CARTXema [Max, Berto y Horaci], SVETMAX [Ayats], FITXEs1-2 [Horaci], PARAuRC [profesor universitario anónimo], MAURIHOR [narrador del cuento de Àngel Mauri]); en otras, por el contrario, el narrador no se identifica con ningún personaje $\mathrm{y}$, por tanto, hablamos de un narrador extra-heterodiegético (archivos 1989HA1, 1990SAL, HELGAHOR, 1991HA2, 1992CUI, DLF1-8, 1993JAR, OSWALDLF, VARVABER, ultim i ClOENDA). Además, el texto consta de dos paratextos que actúan de marcos de la narración: un prólogo y un epílogo firmados por el autor que sirven de instrucción de lectura y, todavía más, inician una reflexión sobre los mecanismos de elaboración de la novela. En este sentido, el carácter metaficcional de la novela de Pagès Jordà pone de manifiesto la condición irónica de la propuesta en un planteamiento que tiene como centro mismo la concepción de la realidad como medio de conocimiento del mundo. Por eso, en el presente trabajo, nos proponemos revisar las diferentes modalidades de la ironía presentes en la primera novela de Vicenç Pagès Jordà: más concretamente, pondremos la atención en las reflexiones metaficcionales a cargo de los narradores y de los personajes, y las ironías verbales; la profusión y variedad de los recursos irónicos utilizados nos indica que estamos delante de una novela irónica que, además, plantea las bases para la reflexión, el desarrollo y la exploración de la ironía en la obra posterior del autor catalán.

\section{LA METAFICCIÓN IRÓNICA}

Linda Hutcheon, en su libro Narcissistic Narrative. The Metafictional Paradox, define la metaficción como una "fiction about fiction -that is, fiction that includes within itself a commentary on its own narrative and/or linguistic identity" (1). Hablamos, por tanto, de una autoconciencia de escritura ficcional 
desde donde se descubre -se explicita- una reflexión sobre la concepción del género $\mathrm{y}$, en definitiva, "sobre el seu caràcter d'indagació del real més enllà de la ingenuïtat de l'estètica realista" (Gregori Soldevila 138-139). Por tanto, debemos admitir que la metaficción maniobra sobre estas convenciones, lo que implica que cualquier transgresión de las convenciones literarias establecidas entre el autor y el lector "funcionen com a recursos per a posar de manifest l'artifici i deixar al descobert el procés de construcció del text" (Gregori Soldevila 139). Patricia Waugh remarca la característica esencial de este mecanismo: dejar al descubierto las artimañas de la construcción novelística: "Metafiction is a term given to fictional writing which selfconsciously and systematically draws attention to its status as an artefact in order to pose questions about the relationship between fiction and reality". En la medida en que se plantea desde una mirada crítica a los propios métodos de construcción de la ficción, "such writings not only examine the fundamental structures of narrative fiction, they also explore the possible fictionality of the world outside the literary fictional text" (2). Si nuestro conocimiento del mundo es interpretado a través del código lingüístico, no es extraño que la ficción literaria (es decir, un mundo constituido completamente de palabras) pueda llegar a ser un medio útil de conocimiento de la realidad. En otras palabras, las novelas metaficcionales tienden a estar construidas a partir de una oposición entre la construcción de una ilusión ficcional y la evidencia de esta construcción. De aquí, pues, el conflicto entre realidad y ficción:

Metafiction functions through the problematization rather than the destruction of the concept of "reality". It depends on the regular construction and subversion of rules and systems. Such novels usually set up an internally consistent "play" world which ensures the reader's absorption, and then lays bare its rules in order to investigate the relation of "fiction" to "reality", the concept of "pretence" (Waugh 40-41).

Esta circunstancia pide del lector un papel activo en el proceso de interpretación de la novela, de manera que éste se transforma en "fully active player in a new conception of literature as a collective creation rather than a monologic and authoritative version of history" (Waugh 43). En el caso de El món d'Horaci, hay dos elementos que aparecen como recursos metaficcionales claros: las referencias al proceso de elaboración, construcción y ordenación de la novela como ficción y la voluntad de desdibujar al autor. 


\subsection{LOS PARATEXTOS METAFICIONALES}

\subsubsection{El prefacio y el postfacio irónicos}

La novela empieza con un "Pròleg inevitable" firmado por V.P. y fechado en Barcelona en 1995 que podemos asociar sin duda alguna al autor real del texto, eso es, Vicenç Pagès Jordà. Por tanto, siguiendo la propuesta de Genette (Seuils 181-188), estamos ante un prefacio auctorial original auténtico denegativo en el que el autor pone en conocimiento del lector los sucesos previos que motivan la aparición de la obra y que puede ser leído como una transformación irónica en clave metaficcional del prólogo clásico. En este caso, la ironía reside en la denegación, que contrasta con lo que nosotros constatamos en otros elementos del paratexto y también por la reflexión que inicia, como instructivo de lectura. Más concretamente, el autor traspasa la responsabilidad de la escritura del texto a un personaje de ficción, Lísia, de manera que desdibuja y altera su propia imagen. No podemos olvidar que la autoría del texto es aquella que viene consagrada por la autoridad de la portada y del copyright, que, en este caso, corresponde a Vicenç Pagès Jordà. La ironía, sin embargo, se centra en presentar al autor real como narratario de un texto cuyo narrador es un personaje de ficción. De esta manera, el texto inicia una reflexión sobre los vínculos entre ficción y realidad y, en definitiva, de la idea misma de realidad, lo que lo identifica como metaficcional.

El autor se presenta como el simple editor de unos archivos informáticos encriptados en un ordenador de una de las oficinas de la Torre Mapfre de Barcelona donde trabaja. Así pues, hemos de entender el texto como un ejemplo, en tono irónico, de una de las funciones más habituales de los prefacios auctoriales denegativos: la exposición de las circunstancias dentro de las cuales el pseudo-editor ha tenido acceso al texto (Genette, Seuils 284) que, en este caso, viene acompañado de un conjunto de referencias a la gestación y proceso de organización de la "novela", a través de una serie de afirmaciones que plantean las relaciones entre la ficción y la realidad (Genette, Figures III 261-265). Así pues, el escritor localiza los archivos y apunta que "segons tots els indicis, davant meu hi tenia els capítols d'una novel·la o de les memòries de Lísia" (19). Pero la afirmación desemboca en realidad en una tematización abierta sobre diferentes aspectos de la creación literaria y, más concretamente, sobre la voluntad de distanciamiento entre realidad y ficción. Así, el escritor se declara incapaz de adivinar si se trata de una autobiografía o de una obra de ficción, aunque reconoce que "alguns 
indicis afavoreixen la segona hipòtesi: més d'un personatge sembla inspirat, tant per l'aspecte físic com pel caràcter, en els empleats amb qui compartia la sala" (20). En cambio, "la hipòtesi de l'obra autobiogràfica es beneficia del realisme de moltes localitzacions i d'alguns detalls que he pogut comprovar personalment $[\ldots]$, tot $\mathrm{i}$ que aquestes circumstàncies també poden donar-se en una novel·la" (20). Finalmente, después de asegurar la ordenación correcta de los archivos que conforman la novela y de explicarla al lector, el escritor remarca la intención de sus intervenciones a lo largo del texto: "M'he marcat el propòsit d'eliminar dels arxius de Lísia la molesta confusió entre realitat i ficció que impregna tant el periodisme com la literatura dels nostres dies. Les meves notes al peu no pretenen ser més que comentaris, pistes que espero que en el pitjor dels casos el lector indulgent em sabrà perdonar" (23). Sin embargo, la práctica de este prefacio, como del postfacio que veremos a continuación, va unida a la puesta en escena de la ficción misma y, pues, "ne fait qu'exacerber en l'exploitant la tendance profonde de la préface à une self-consciousness à la fois gênée et joueuse : jouant de sa gêne" (Genette, Seuils 295).

Eso explicaría también, por ejemplo, la aparición de unos mismos personajes en narraciones diferentes. Si en la novela realista el objetivo de este recurso es alcanzar un mayor grado de veracidad, una imitación más creíble de la realidad, en la novela de Pagès tiene una intención claramente lúdica: la doctora Carla Romans "especialitzada en llengües semítiques i en l'hermenèutica de textos sagrats" que ayuda al escritor en la resolución de diversos enigmas en la novela es una filóloga que en "Cercles d'infinites combinacions" mantiene una cierta relación con el narrador y también lo ayuda a resolver un misterio sobre un grupo de hermeneutas fabrianos.

Algo parecido ocurre, como hemos dicho, en el postfacio auctorial original auténtico denegativo que cierra la novela, titulado "Apèndix", firmado nuevamente como V.P. e igualmente fechado en Barcelona en 1995. Ahora, el narrador continúa jugando, hasta las últimas consecuencias, con el papel de negación de responsabilidad narrativa sobre el texto y reconoce que "subsisteixen uns quants punts foscos" en el relato e incluso deja en manos del lector la decisión de escoger el final que más le convenga, en una reflexión sobre el mismo texto literario:

L'el·lipsi final podria tenir la funció d'oferir diverses interpretacions als lectors, cadascun dels quals podria construir el seu propi final segons que les suposicions i sospites d'Horaci en relació amb la 
conxorxa mediàtica fossin certes o no. Una altra possibilitat és que Lísia deixés el final a punt [...], però que mantingués punts foscos en la trama amb la intenció d'anar-los omplint a mesura que els anés esbrinant -o inventant-, però que finalment, per alguna raó que se m'escapa no ho dugés a terme (375).

Todavía más, para asegurar esta segunda hipótesis, el autor recorre a otro recurso metaficcional, la metalepsi, un fenómeno definido por Genette como "cette transgression délibérée du seuil d'enchâssement" según el cual "un auteur (ou son lecteur) s'introduit dans l'action fictive de son récit ou [...] un personatge de cette fiction vient s'immiscer dans l'existence extradiégétique de l'auteur ou du lecteur" (Nouveau discours du récit 58). El ejemplo del que hablamos pertenece a esta segunda posibilidad, ya que el autor nos transcribe la conversación que mantiene con la doctora Carla Romans, ente de ficción, sobre la posibilidad que "Els arxius de Lísia" sea, en efecto, una novela. La visión de la doctora desemboca en una reflexión sobre el grado de verosimilitud del texto como ficción o realidad y, nuevamente, se pregunta "si els arxius de Lísia formaven una novel·la o si eren el relat en clau d'algun fet real" (380), a pesar de que, nos asegura, ha comprobado que algunos de los personajes presentes en la novela no existen. Al fin y al cabo, ambos paratextos se complacen en cuestionar el estatus ficcional de la novela y establecen una ambigüedad de carácter lúdico gracias a esta ruptura entre ficción y realidad; una ambigüedad que tiene un alto rendimiento metaficcional y permite la lectura autoconsciente de la novela.

\subsubsection{Las notas a pie de página}

No podemos cerrar este apartado sin abordar uno de los elementos paratextuales más destacados de la novela: las ciento treinta y seis notas auctoriales originales auténticas denegativas a pie de página que acompañan el relato y que refuerzan la idea de un autor que se presenta como un editor encargado "simplement" de editar un text que se le ha entregado o ha encontrado (Genette, Seuils 342). Ahora bien, las notas "sous les couvert d'une simulation plus ou moins satirique de paratexte, contribuent à la fiction du texte" (Genette, Seuils 345). En nuestro caso, estamos ante un uso irónico de este tipo de notas: se presentan como una transformación lúdica del paratexto, hecho que imprime el carácter ficcional de las mismas, en la medida en que desnudan el procedimiento narrativo y muestran el carácter imaginario y manipulable de la historia narrada, en cuyo caso, como señala Carme Gregori (145), se pone 
"sota sospita el contracte ficcional tradicional -que consisteix, com és ben sabut, a fer oblidar que es tracta d'una ficció" i accentua "l'autoconciència del text”. Así pues, en una ocasión, ante la primera referencia al pozo del jardín de la casa donde viven los protagonistas, el autor incorpora una referencia a pie de página para advertirnos de la importancia del depósito en el argumento y, además, emite valoraciones sobre el capítulo 41):

El lector farà bé de recordar aquesta primera referència a un element que resultarà clau en el desenvolupament de la trama. La funció principal d'aquest capítol no és només la de servir d'introducció a les relacions entre Max, Berto i Horaci, sinó també presentar de manera subreptícia el pou. De fet, el pou apareix en cadascun dels cinc arxius encapçalats per la xifra de l'any, que en la meva proposta d'ordenació formen l'esquelet de la novel'la.

En otra ocasión, comenta otros aspectos de la narración relacionados con la construcción de los personajes y nos avanza algunas primicias: "Aparentment, l'única funció de BIQUIBER és arrodonir la presentació de Berto, el tercer habitant de Vil·la Barrochio. La trama dels arxius de Lísia comença a dibuixar-se a partir del capítol següent, cosymB, que presenta el personatge anomenat Ymbert" (53). En la gran mayoría de intervenciones, el autor explica algunas palabras de los "diferents argots" de los personajes; tanto es así que, de entrada, decide clasificarlos:

Una lectura atenta dels seus diàlegs en permet descobrir com a mínim de tres menes: un argot genèric, utilitzat habitualment en determinades capes sòcio-geogràfico-generacionals (birra, hinyar, mais), un de particular usat només per en Max (Bog, bratxni, hourrouxou, ptitsa) i un de circumscrit a la Vil·la Barrochio (corróman, indijoe, sibemoll). Generalment, el sentit d'aquestes paraules es pot deduir a partir del context. Tot $\mathrm{i}$ que la frontera entre els termes comprensibles i els que no ho són depèn de cada lector, he introduit notes explicatives a peu de pàgina en els casos que he trobat particularment abstrusos (46-47).

Otros ejemplos incluyen definiciones del Diccionari català-valencià-balear, de los estudios etimológicos de Joan Coromines y del Diccionari de la Llengua Catalana; relaciones de algunos elementos de la novela, generalmente personajes, con otras referencias (películas, novelas, personajes ilustres); traducciones del latín, del inglés, del alemán y del japonés; citaciones de obras literarias (El Quijote, las Rondalles de Jacint Verdaguer, la Bíblia, El 
péndulo de Foucault de Umberto Eco...); aclaraciones sobre la variedad dialectal del catalán usada por los personajes; consultas lingüísticas y esotéricas aportadas por la doctora Carla Romans; descripciones sobre volúmenes de libros; citaciones bibliográficas de estudios relacionados con el tema del que se está hablando, entre otros.

Queremos identificar algunos más, como la que encontramos cuando V.P. interrumpe el discurso narrativo y, en pie de página, opina sobre Lísia a partir de una descripción bien particular sobre la comida de Berto: "Des del primer moment que vaig llegir aquest passatge treballo amb la hipòtesi que l'autor és vegetarià" (161); o localiza algunos errores o "lapsus" del narrador, como indica en el archivo 1993JAR: "A l'arxiu 1990sal Berto tenia els cabells "castanys tallats curts". Probablement el canvi de color es deu a un lapsus de Lísia" (279). Algunos errores son, directamente, contradicciones a los sucesos de la novela: en el archivo VARVABER, dedicado a describir la relación entre Varvara y Berto, ella se despide diciendo "Ja ens veurem" pero el editor contradice la versión y añade: "Fals: malgrat les expectatives que suscita, Varvara no tornarà a aparèixer" (349), de manera que deshace las expectativas creadas por la ficción narrativa. En otra ocasión, el autor se distancia de la opinión de un personaje y explicita la estrategia ficcional de manipulación de datos cuando Horaci se dedica a glosar algunos apellidos para establecer conexiones entre personajes y sucesos a partir de razonamientos ortográficos. En este caso, el autor-editor nos advierte que la aplicación de Horaci es totalmente manipulada y, por tanto, falsa: primero, respecto del protagonista de Citizen Kane, que no es James Foster Kane sino "Charles Foster Kane, de manera que las inicials serían CFK" y no JFK, como las del presidente americano asesinado; seguidamente, con el juego entre George Orwell, Orson Wells y H. G. Well, deshecho por el apunte del editor: "Més trampes: per fer quadrar el raonament ortogràfic, Horaci omet la segona $e$ del cognom Welles i la $s$ de Wells, igual com abans ha eliminat la $h$ d'Agartha" (324).

\subsubsection{Los epígrafes}

Brevemente, queremos hacer notar también dos intervenciones que, en este caso, afectan a dos de los epígrafes que encabezan cada uno de los cinco capítulos en los que se distribuyen los archivos, añadidos por el supuesto autor de la novela y que es necesario leer desde un efecto irónico: el primer caso tiene que ver con una citación de Nina Kazi que dice "There's nothing but show-biz" y que, además de establecer un juego con los epígrafes de 
los capítulos anteriores ("There's no business like show business" [Irving Berlin] y "There's no business but show business" [Neil Postman]), éste último se trata de un epígrafe falso ya que, como anota el editor: "No he trobat enlloc cap referència sobre aquest presumpte personatge. En canvi, he descobert que en swahili nina kazi significat «Estic molt enfeinat»" (115). El segundo caso tiene que ver con una citación de Tres sombreros de copa, de Miguel Mihura, que dice: "Hizo “pun!”, y acabó todo" (369), en cuyo caso el editor aclara que, más bien, "A la frase de Mihura hi diu "pin"”. En los dos casos, vemos que el uso del epígrafe permite también al autor recrearse en una transformación lúdica del "effet-épigraphe" (Genette, Seuils 163), de filiación prestigiosa, a través de la cual se quiere dar la impresión de alto nivel cultural, de intelectualidad. Más allá de la simple idea de afección intelectual de esta práctica textual, aquí debemos concebir el epígrafe como una estrategia intencionada de inscripción de la obra literaria dentro de un ámbito de pensamiento o de una línea de producción ideológica o estética. A través de esta relación, pues, el autor puede utilizar el epígrafe como una carta de presentación de su obra y establece un vínculo de afinidad con uno o diversos autores, o con algún personaje, situación o idea defendida o criticada (Samoyault 47). Sin embargo, en este caso, el uso del epígrafe permite al autor distanciarse del sentido original, situarlo fuera del contexto primero y usarlo como modelo de subversión, lo que activa la lectura irónica del paratexto (Hannoosh 61). Así, los epígrafes reflejan la estética del juego en el texto literario narrativo, por lo que sirven de puerta de entrada a la propuesta lúdica de Pagès Jordà: en los tres primeros casos, como una clave de lectura que sirve para acentuar el contraste entre la realidad (el mundo) y su consideración como mero negocio espectacular; en el último, a través de una reflexión de carácter textual sobre la problemática de construcción de la ficción como vía de conocimiento de la realidad. En todos estos casos, la metaficción, por el hecho de poner de manifiesto las convenciones que el género exige mantener implícitas, establece una distancia entre la pretendida ilusión mimética de la ficción y la conciencia del artificio literario. Así, la atención se centra en la construcción más que en la narración de la propia historia.

\subsection{LA FICCIÓN NARRATIVA COMO PROPUESTA AUTOCONSCIENTE}

Por otra parte, la inversión irónica de las convenciones del género narrativo funciona como un medio que también nos permite poner al descubierto la arbitrariedad de nuestra percepción del mundo y de las imágenes que 
se generan a partir de esta mirada, en una reflexión autoconsciente de la misma novela como género, es decir, en una metaficción. Visto así, El món d'Horaci es una novela que juega a confundir las convenciones que permiten distinguir el relato verídico y la ficción, a través de la inclusión de personajes, situaciones y problemáticas de carácter histórico dentro del contexto ficticio de las obras, lo cual "cuestiona las pretensiones de objetividad y empirismo del discurso histórico" (Juan 24). Sin embargo, no podemos olvidar, como señala Linda Hutcheon, que "both history and fiction are discourses, human constructs, signifying systems, and both derive their major claim to truth from that identity" (Hutcheon, A Poetics of Postmodernism 93). Esta idea se recoge perfectamente, al menos, en una afirmación de la lección inaugural del profesor Deulofeu que relaciona el discurso literario con el periodístico: "L'única diferència entre un periodista i un autor de ficció és que el text creatiu del periodista és rebut com una informació, o sigui, com una veritat que no és valorada segons criteris estètics, sinó segons el grau d'imprevisibilitat, ja que com menys previsible és una notícia, més interès té" (p. 189). Pero la lección inaugural está dedicada básicamente a presentar casos periodísticos cuya información aportada por los periodistas es falsa. No es el único caso. En el archivo 1991на2, Max explica la historia de un cámara que se gana la vida grabando vídeos domésticos falsamente espontáneos con actores contratados y situaciones ensayadas, de manera que acaban grabando "reportatges per vendre a les telis ( $\mathrm{sic}$ ) privades. Un fa veure que és un ionqui, o que està en una secta, o que és etarra: amaga la cara, s'ho inventa tot i després es fan les barbes d'or venent-ho als informatius" (p. 124). Es más, en la medida en que esta relación intertextual se expande no solo a la referencia de otros textos pertenecientes a la tradición literaria sino hacia la incorporación de elementos procedentes de la cultura masiva y popular, "tiende a problematizar el referente de la novela e historia convencionales y aspira a establecer el carácter textual de nuestra experiencia en el mundo" (Juan-Navarro 233). Al fin y al cabo, si la creación y difusión descontrolada de noticias o imágenes hace posible cada vez más la reproducción de este engaño - esta "falsa realidad"-, entonces, en última instancia, es necesario indagar sobre las posibilidades de esta nueva realidad y sobre el concepto mismo de realidad. La tarea del novelista, pues, representado en la figura del autor-editor, no puede ser otra que la de encargado de ordenar los archivos de los que dispone-los signos, si seguimos la analogía del profesor Deulofeu-, y combinarlos según su criterio y voluntad para darles un sentido determinado (Marrugat 48). Como apunta Hutcheon (A Poetics of Postmodernism 55), "Fiction does not mirror 
reality; nor does it reproduce it. It cannot. [...] Instead, fiction is offered as another of the discourses by which we construct our versions of reality, and both the construction and the need for it are what are foregrounded in the postmodernist novel". Por eso, esta ordenación, en cualquier caso, siempre será arbitraria: el mismo V.P. ya nos lo dice en el "pròleg inevitable": "Després de nombroses lectures, hipòtesis i reajustaments, he après a identificar els tipus d'arxius a partir dels nom que Lísia els va donar. D'aquesta manera he aconseguit establir una ordenació que em sembla lògica" (21). Ahora bien, como advierte el autor en un fragmento que recuerda las indicaciones de Rayuela, de Julio Cortázar,

[a]l final d'El món d'Horaci hi he col·locat un índex amb l'ordenació dels arxius que proposo, amb la intenció de fer més clara l'estructuració per la qual he optat. Naturalment, els arxius també accepten altres disposicions. El lector, si ho prefereix, pot començar llegint directament tots els arxius que contenen la indicació de l'any, o bé intercalar-ne d'altres (que és el que m'ha semblat preferible), o bé accedir a la sèrie completa DLF, per exemple (22-23).

Si lo miramos bien, el título del anterior libro de cuentos de Vicenç Pagès, Cercles d'infinites combinacions, ya apunta en esta dirección: así, una ficción es solo una realidad posible entre el resto de combinaciones infinitas. Por eso, no tenemos que leer El món d'Horaci -el título y, por extensión, la novela- solo como una descripción de la vida y de las relaciones de Horaci como personaje sino como ficción, eso es, como mundo posible. Y la tarea del autor no es la de crear, pues, sino la de combinar una serie de archivos informáticos con "una ordenació que m'ha semblat lògica" (21).

De hecho, si nos fijamos, los personajes de El món d'Horaci se construyen también a partir de esta idea y son, en parte, "autores" y recreadores de una nueva realidad que es, por definición, inestable y múltiple pero también particular, individual. Así pues, Ymbert, en el archivo, CosymB, se inventa "l'increïble i això no obstant baratíssim joc de la cutiflinx telèpata" (56), en realidad, un método para encontrar el amor basado en la coincidencia para escoger un metro determinado y subir juntos a él; Horaci le hace una lectura errónea del tarot a Helga interesadamente, como apunta el editor, pero, sin embargo, acierta; Horaci escribe cartas a Helga durante sus viajes a Nueva York, Estambul, Atenas y Florencia pero, cuando llegamos a la última carta del archivo, Helga le responde desde Haifa y sabemos entonces que toda esta relación epistolar es falsa: "Pots escriure'm cartes encapçalades amb 
el nom de totes les ciutats del món, i parlar-me de carrers, bars, esglésies i discoteques de Lapònia o de la Cotxinxina. Pots fer exactament el que vulguis, Horaci, però jo sé que no has sortit del barri” (109). En el archivo 1991HA2, Horaci reproduce el esquema típico de una escena de misterio: "Aquest matí, quan he anat a comprar galetes, he tingut la sensació que algú m'espiava" (119). Más allá, el relato se mantiene: "Després d'esmorzar he tornat a sortir per veure si em continuava seguint... i, no hi havia dubte, la sensació no m'abandonava" (120). Pero el misterio se desarma cuando Horaci reventa el tópico y confiesa que el supuesto espía es, en realidad, "[u]na papallona groga, d'un groc apagat, petitona, que anava volant a prop del meu cap i que al final s'ha aturat sobre una clavellina, amb delicadesa ancestral" (121). En el primer apunte de su blog en la novela, Horaci defiende el argumento que considera que "l'amor és una funció" y, en efecto, aplica los diferentes tipos de funciones matemáticas para explicar y dibujar las distintas "enginyeries matrimonials" y hasta asociar una de ellas a la relación que mantiene con Helga ("Helga, el nostre amor serà carrat o no serà" [148]), cuya evolución, sin embargo, nunca llegaremos a conocer. Max, Berto y Horaci escriben una carta al director firmada con el anagrama Txema Barrochio con la "l'íntima necessitat" de comunicar que "no sóc el qui apareix a la fotografia que encapçala la secció de Societat del dia del solstici d'hivern", que "la dama que apareix a la fotografia tampoc no és l'esposa" y que, por si quedaba alguna duda, "ni el meu nom ni els meus cognoms coincideixen amb els que el peu de la fotografia atribueix" (200-201). Leemos la historia amorosa entre Max i Svetlana como real pero, en realidad, Max añade (o el editor así nos lo dice) elementos que son propios de la ficción. Nos lo advierte el autor: a partir de un cierto momento,

el relat del nostre heroi es torna incoherent. No, ja sé que no t'ho ha explicat mai, ni ho farà, però tu i jo sabem que en Max certes coses no te les confessaria mai de la vida, i a mi sí, diguem que per tradició. Cada cop que m'ho explica hi afegeix una mica de salsa, tot i que no segueix mai una progressió cronològica i que sempre comença i acaba la narració en moments diferents, de manera que ja no sé si quedar-me amb l'última versió perquè va recordant detalls o amb la primera perquè no hi afegeix. D'altra banda, alguna de les escenes que hi afegeix les ha tretes d'històries que li he explicat jo mateix, magnificades de la manera que li és pròpia (227-228). 
Otro ejemplo de este juego entre realidad y ficción lo encontramos en el archivo OSWALDLF, cuando Horaci descubre al profesor Deulofeu en la fotografía de Robert Jackson del 24 de noviembre de 1964 en la que se muestra el asesinato de Lee Harvey Oswald mientras era trasladado a la prisión del condado de Dallas y que, además, sirve de portada del libro de Pagès. Según sabemos, el profesor Deulofeu se identifica en la ficción con uno de los periodistas presentes para informar de la noticia del traslado del asesino del presidente de los Estados Unidos, John F. Kennedy. En efecto, la descripción coincide con la del individuo de la fotografía real: en el extremo derecho, entre el hombre del puro y el inspector tapado por Ruby está "l'única persona que mirava l'escena sense reflectir cap emoció. Aguantava un enorme micròfon amb la mà, a l'altura del pit, i presenciava l'assassinat amb posat seré. Duia la mateixa gavardina que durant la lliçó inaugural. El pentinat i les ulleres també eren si fa no fa idèntics" (306). La relación entre el individuo de la fotografía y el profesor de El món d'Horaci apunta hacia un tipo de narración autoconsciente que juega con el material histórico y el grado de veracidad que puede adquirir éste dentro de la ficción, un mecanismo metaficcional más que, ahora, plantea una brecha entre la realidad y la ficción. Así, el autor utiliza el conocimiento enciclopédico del lector de que Kennedy y Harvey Oswald sí existieron realmente (así como la fotografía del asesinato del segundo de Jackson con la que ganó el Premio Pulitzer de fotografía en el año 1964 o la celebración de los Juegos Olímpicos de Barcelona en 1992) para plantear una reflexión abierta sobre las ideas preconcebidas que el lector tiene sobre qué es realmente la 'verdad' histórica; una idea que conecta la novela con los planteamientos utilizados por Linda Hutcheon para caracterizar la novela postmoderna ${ }^{3}$. Así mismo, otro de los elementos que conviene analizar es la imagen de la ciudad en relación con la transformación urbana y urbanística que

\footnotetext{
Vicenç Pagès Jordà es autor de los prólogos de las traducciones de dos libros de David Foster Wallace: L'aigua és això (Edicions del Periscopi, 2014) i Antologia de contes (Edicions del Periscopi, 2016). En el primero, Pagès Jordà señala, entre las trece razones por las que le gusta la obra de F. Wallace, queremos destacar tres que son, al menos, coincidentes con El món d'Horaci: "DFW va saber incorporar la no-ficció dins la ficció i viceversa. La seva família sabia que gran part dels reportatges eren inventats, però llegia amb molta atenció les novel·les perquè s'hi trobaven a ells mateixos". Además, el escritor inglés construye "personatges poliaddictes, alternativament hipersensibles i hiposensibles" que permiten adentrarse "amb fermesa en el pitjor de nosaltres mateixos" y "és autor de les notes a peu de página més maníaques, desaforades i retroalimentadores que conec". Ambos prólogos se pueden encontrar, además, en la página web del escritor: http://www.vicencpagesjorda.net.
} 
experimentó Barcelona como consecuencia de la organización de los Juegos Olímpicos de 1992, "un canvi d'escala i l'entrada de Barcelona en els circuits internacionals. Van comportar la desaparició d'alguns espais tradicionals, la creació de nous barris i equipaments, i la introducció d'un cultura urbana" (Guillamon, La ciutat interrompuda ... 215). Una transformación que debemos asociar con la nueva cultura urbana de los años noventa, sobre todo en lo que respecta a las dificultades de los personajes para relacionarse con el entorno o, incluso, con la sociedad. De hecho, la novela desplaza el punto de atención de la ciudad al departamento en el que viven los tres protagonistas, por lo que las descripciones de Barcelona se reducen casi a la mínima expresión. Sin embargo, se hace referencia a algunas consecuencias urbanísticas como la construcción de rascacielos: "l'empresa tenia les oficines a la Torre Mapfre, un dels dos gratacels bessons i encarats al Mediterrani que es van construir amb l'expansió olímpica de Barcelona" (9); los atascos vehiculares o la masificación de los medios de transporte públicos: "enlloc he trobat tantes empentes, tanta asfíxia, tanta pudor de suat i tanta misantropia com als trens que surten de la plaça Catalunya i van a Bellaterra carregats d'estudiants insensibles al deshonor" (136). Por el contrario, las referencias a alguno de los aspectos relacionados con los Juegos Olímpicos están connotados negativamente. Encontramos un ejemplo en la opinión que Horaci tiene sobre el diseño de Cobi, la mascota de los juegos olímpicos catalanes, obra del diseñador Xavier Mariscal: "Qualsevol creador raonablement pitagòric hauria dissenyat una mascota olímpica en forma de cercle. Però no, ell s'ha conformat amb un mer musell logarítmic, i a ningú se li ha acudit prendre la plaça San Jaume" (142). En otra ocasión, la crítica se dirige, desde los medios de comunicación de masas (en este caso, la televisión), a los esfuerzos negativos del ayuntamiento de la ciudad con el fin de ofrecer a los visitantes y deportistas una mejor imagen de Barcelona: “Obre l'aixeta quan de la saleta ja se sent la veu de Jordi Llompart informant de les mesures que va prendre l'Ajuntament de la ciutat per amagar els indigents mentre se celebrava l'espectacle olímpic" (170); o los procesos de movilidad poblacional dentro de la ciudad, representados en la novela por una familia gitana con una cabra adiestrada que pide limosna por las calles de Gràcia y que es descrita desde la mirada de uno de los personajes, Berto, de una manera también negativa: "em fa terror. Em fa terror quan [...] la nena gitaneta em veu a la finestra i s'acosta $i$ toca el vidre amb els seus dits negres i llargs d'ungles negres i llargues i punxegudes, i em diu que no m'amagui que m'ha vist, i jo no puc moure'm de darrere la persiana i sóc incapaç de donar-li un duro i em sento com un 
malparit, sabeu?" (284). Ahora bien, más allá de los "llocs sinistres situats al voltant dels centres urbans" identificados por Horaci, nuevamente, el archivo SVETMAX es ideal para explicar este tratamiento de la realidad: "l'irrepetible agost del 92, barres d'or i sang i anells de cinc colors sobre fons blanc a tots els balcons de Barcelona, i els cossos més bells del món passejant entre Colom i Canaletes" (215). Sin embargo, más allá de lo que parece el inicio de un gran elogio a la Barcelona olímpica, es en realidad un retrato irónico reducido a aspectos como el tratamiento de la mujer como objeto sensual y sexual de los espectadores, a través de una descripción que no se basa en sus habilidades deportivas sino físicas y sociales, "totes olímpiament desitjables fent turismo la nuit per una Barcelona saludable y vigorosa, segons elles i la premsa estrangera" (220); o más adelante, cuando apunta que "a la Vila Olímpica de Barcelona les màquines expenedores de condons es buidaven a un ritme vertiginós, i a l'últim els del COOB en van haver de repartir a grapats de franc, i ni així donaven l'abast" (222). En conjunto, pues, a través de la perspectiva de los protagonistas, El món d'Horaci ofrece un retrato que va más allá del reporte meramente informativo, típico de los medios de comunicación y, bien al contrario, ofrece una visión mucho más subjetiva y transgresora, focalizada en la opinión o la construcción de los personajes. En este sentido, se ajusta al funcionamiento de la novela postmoderna que apunta Linda Hutcheon en A Poetics of Postmodernim (109), la cual "select, construct, and render self-sufficient and closed a narrative world that would be representational but still separate from changing experience and historical process". Por eso, la descripción que Ayats hace de Svetlana según el testimonio de Max hace constantes referencias a su físico escultural no con el fin de destacarla como deportista de élite (de hecho sabemos que no consigue ninguna medalla olímpica, a pesar de ser sus últimos juegos) sino como objeto sexual.

De esta manera, la novela, más que dedicarse al desarrollo de la ficción, se convierte en un texto autoconsciente que, por una parte, pone al descubierto el artificio de la ficción y habla de la misma literatura, del proceso de construcción y de los códigos y convenciones de la ficción y, por otra, plantea una reflexión sobre los límites de comprensión e interpretación de la realidad desde el contexto espaciotemporal dentro del cual se desarrolla (aunque no desde la perspectiva historicista que Hutcheon plantea a partir del concepto de metaficción historiográfica). En este sentido, El món d'Horaci, como novela metaficcional, tiene un carácter antirrealista en la medida en la que no refleja el mundo externo sino que tiene como principal objetivo la autorreferencialidad: "el trencament 
de la il·lusió mimètica que suposa la manifestació de l'autoconsciència, el fet que el procés d'escriptura es convertesca en centre d'atenció de l'escriptura, l'afirmació de la ficcionalitat, tot plegat, ve a demostrar que l'única "realitat" de què s'hi tracta és l'escriptura" (Gregori 148). Desde esta perspectiva, entendemos la yuxtaposición de narraciones como el punto de vista de una reflexión sobre los mecanismos de reproducción e instrucción del relato, y sobre el grado de "verdad" que se otorga a la ficción. Si nos fijamos bien, por una parte, desconocemos cuál es el orden original en el que el autor ficcional de la novela escribió y organizó los archivos y, por otra, sabemos que el orden en el que leemos ahora los textos es solo una voluntad del autor real de crear un sentido "lògic". En este sentido, El món d'Horaci es más que la historia basada en los sucesos que ocurren en una casa de estudiantes en el barrio de Gràcia entre los años ochenta y noventa o, también, la investigación iniciada por uno de los protagonistas, Horaci, por entender el significado del mundo. Más allá del argumento, el lector se siente constantemente llamado a reflexionar sobre los múltiples elementos que conforman la ficción, ya sea el lenguaje utilizado, la construcción de los personajes o el cuestionamiento del grado de "realidad" de la ficción y, de rebote, del proceso de escritura. Así, como apunta Ballart (449-450), "la ironía, al subvertir esa ilusión, no persigue sino crear otra nueva, mucho más consistente puesto que tiene su base en una superación de la simple credulidad y en la idea, común a autor y lector, de una literatura autoconsciente".

\section{LAS IRONÍAS VERBALES}

Otro de los recursos irónicos más efectivos en esta primera novela de Vicenç Pagès es la comparación, con multitud de ejemplos. Niogret (69) identifica como comparaciones irónicas aquellas en las que se embellece la realidad a la vez que el autor deja entrever que este embellecimiento no se justifica. Es lo que ocurre, por ejemplo, cuando, en el archivo 1989HA1, el narrador describe el cucharón que usa Max para pintar la pared como "una espàtula veloç en mans d'un bàrman del Copacabana" (33) y, seguidamente, puntualiza que "Titanlux sona com el nom d'un combinat refrescant i potser afrodisíac" (33-34). También cuando, en una descripción de la ciudad de Barcelona, el narrador identifica un chico gordo con una "truja marina" (56). Más adelante, en el archivo 1992CuI, el narrador embellece irónicamente el proceso de cocina de Berto y afirma que las salpicaduras de aceite cuando deja caer 
un trozo de bistec al sartén "s'afegeixen al neopuntillisme Lichtenstein que impregna les rajoles de la paret" (160), en referencia al artista estadounidense. Más adelante, Ayats, en el archivo svetMAx, describe Svetlana desde una comparación irónica cuando afirma que "s'expressava amb la passió d'una hostessa repassant les instruccions en cas d'accident aeri" (230), un hecho que claramente contrasta la pasión con el acto designado.

Si la comparación posee los atributos de un comparador de manera excesiva, hablamos de comparaciones hiperbólicas (Niogret 76), per ejemplo, cuando el narrador describe el humo del "peterstiuvesant" de Curri que caracolea el centro de la mesa "com una galàxia en formació" (69); o cuando Ymbert, en el archivo 1990sal, encuentra a Cosima en la televisión y describe la emoción que siente "com si tingués una tribu zulu al pílor!" (92). Tenemos otro ejemplo cuando Max describe la mirada de una pareja motera después de que estén a punto de atropellarlo "com si jo fos un indígena i ells els conquistadors de l'espai" (128), después de que Berto haya ignorado un paso de cebra "com una casa de pagès" (127). En este sentido, el archivo svetMax, en el que se narra el encuentro entre la olímpica Svetlana i Max es muy productivo en hipérboles como, por ejemplo, cuando el narrador-Ayats-, habla de los diferentes prototipos de mujeres olímpicas y describe las atletas como una "carrosseria aerodinàmica de les topmodels de l'atletisme" $\mathrm{o}$, inmediatamente, a las atletas norteamericanas, jamaicanas, cubanas y nigerianas como "gaseles d'ungles griffith i natges-d'eben envernissades amb líquids lubrificants" (216).

En otras ocasiones, estas comparaciones irónicas pueden degradar el comparado y rebajarlo a un nivel inferior al de la comparación. Ocurre, por ejemplo, cuando el narrador compara el fragor del rodillo de pintar con "una batalla de llimacs o un ramat de dromedaris arrossegant-se per un pantà" (36); o, más adelante, cuando compara el hecho de servir la pintura desde el cucharón a los rodillos para que absorban mejor "com si servissin arròs bullit sobre un braç amputat" (39). También cuando, para describir una cajonera blanca que los tres amigos toman de un contenedor, apunta que estaba "bruta com cul de mona caputxina" (44) y, más tarde, cuando se detiene a hablar del caldo de Berto y dice: "El caldo de cultiu està format per diverses capes de líquid, com si els components s'haguessin anat separant, ofesos pels canvis de temperatura i d'ambient, pel pas des dies o - més probablement - per les males companyies" y, más adelante, lo describe desde "tots els espectres del marró i el verd, com llot d'aiguamoll, i una colònia de tàvecs no se'n sentiria estranya" (161). 
Las comparaciones grotescas son otro de los recursos presentes en $\mathrm{El}$ món d'Horaci que podemos interpretar desde la ironía. En este caso, las cualidades del elemento comparado se rebajan de manera excesiva, ya que se ocupan comparados muy alejados. Es lo que ocurre, por ejemplo, cuando Berto describe a dos jóvenes que quedan en topless en la playa y se estiran de cara al sol "com si s'hi oferissin en sacrifici" (49). En otra ocasión, en el archivo cosymb, Ymbert habla del guardia de seguridad del metro, que lo vigila "mirant-me com a una tifa de vaca que es negués a trepitjar" (61); cuando el narrador describe a Horaci sentado "amb cara de fatiga d'esfínter (69); cuando Horaci dice que mira a Max "com aquell que mira una rata de claveguera" (136); o cuando el narrador describe a los pretendientes que rodean a Svetlana en la discoteca com "voltors estenent les ales" (227) o, más adelante, habla de "l'impacte d'una minúscula partícula de saliva svetlanesca" en el labio superior de Max y éste la recoge "[a]mb una llepada veloç, de gripau en zel" (230). Finalmente, en el archivo VARVABER, el narrador describe la relación sexual que mantienen Berto i Varvara a través de una comparación hiperbólica: "Ella el xuclava com si fos un refresc a través d'una palla que era el seu membre-tub" (343).

De la misma manera, los diferentes narradores de la novela también utilizan la hipérbole como recurso irónico, sobre todo en la descripción de personajes o de elementos. Así pues, la visita a los contenedores para completar el mobiliario de la casa es definida como "la pensada d'anar de safari" (42) e identifica a los "drapaires, quincallaires i revenedors" como un conjunto de "màfies organitzades" (43). En otra ocasión, la "vena creativa" d'Ayats es descrita de manera hiperbólica por Berto y dice que "quan se li desboca [...] és capaç de vendre un submarí de propulsió nuclear a Petra Kelly" (75), en referencia a la activista alemana, reconocida, entre otras acciones políticas, por las numerosas campañas por la paz i la ecología. También es hiperbólica la descripción del temblor de rodillas de Max en el archivo svetmax cuando Ayats dice que era "de magnitud Parkinson terminal" (231). El narrador del archivo 1992cuI, describe la comida que ha preparado Berto y se siente incapaz de adivinar de qué se trata: "una llesca vermella i rígida, que en el període precambrià podia haver estat un bistec" (160). Pero este recurso se amplía hiperbólicamente y se aplica al momento final de la presentación del plato (160-161):

El contingut del plat d'en Berto deu pesar unes dues lliures. Hi floten una mena d'orelles de mixo, que també podrien ser rovellons torrats 
al límit de la putrefacció o cansalada triquinòsica tallada a triangles i afogada en oli de colza. Al costat hi semifloten unes partícules menudes, d'un blanc trencat i aparença teguminosa: tendrums de conill?, ossos liqüefactats?, ungles de pollastre?, articulacions rebels a l'ebullició?, ulls de rosegador?, culs de cargol tumefacte?, timpans de marsupial?, forúnculs senils?, gargaix de tísic?, pòsit de clenbuterol? $\mathrm{Ni}$ en Berto fa cara de saber-ho del cert.

La investigación al entorno de los sentidos del lenguaje es también un mecanismo irónico presente en El món d'Horaci, a través de los juegos de palabras, la desautomatización de los usos estereotipados o la interpretación en sentido literal de palabras o expresiones que utilizamos normalmente en sentido figurado. De esta manera, el autor explota los desajustes entre lenguaje y referente y dota a palabras o frases de un sentido imprevisto. En esta línea, podemos identificar, en primer lugar, el juego lingüístico anunciado por el mismo escritor (395), situado en la primera frase de la novela: el autor-editor dice que trabajaba en "revistes científiques i per a noies [paranoies]" (9). Como sabremos en el último archivo, Horaci también acabará trabajando como responsable de una sección de revista juvenil llamada Per a noies escric (372). Por otra parte, encontramos otro ejemplo cuando Horaci escribe una carta desde Nueva York, le cuenta a Helga que vive en unos antiguos almacenes y describe el propietario como un "yuffie (young urban failure, com un yuppie però en fracàs)" (103); o cuando Ayats, en el archivo SVETMAX, describe la tarjeta de identificación de los miembros olímpicos como "escapulari" (225), disimulando el sentido original religioso. Un ejemplo de reinterpretación de sentidos literal/figurado lo encontramos en el archivo 1993JAR cuando, después de que Berto haya contado una historia de miedo, Max exclama: "Hosti, Berto, m'has deixat glaçat" y Horaci responde: "Deunidó. Però també és veritat que a aquesta hora comença a fer fresca". En este caso, Max utiliza el sentido figurado considerado en el Diccionari català-valencià-balear, "paralitzar per una impressió forta, especialment de por, sorpresa, dolor, etc." (Alcover y Moll s.p.) pero Horaci hace una reinterpretación literal asociada a la temperatura ambiente. El otro ejemplo, el último de este apartado, también es de Horaci, esta vez como narrador del archivo BLOCHOR4. Ahora utiliza la frase hecha "ésser més clar que l'aigua", registrada en el Diccionari català-valencià-balear con el sentido de "ésser evident, o parlar amb molta franquesa, sense pal-liatius" (Alcover y Moll s.p.) para transformarla y puntualizar: "Més clar, aigua diürètica i de baixa mineralització embotellada al Montseny (sense glaç, sisplau)" (363). 


\section{CONCLUSIONES}

El análisis detallado de la ironía en El món d'Horaci, la primera novela de Vicenç Pagès Jordà, nos ha permitido comprobar la importancia que el autor otorga a este concepto tan resbaladizo y multiforme, de manera que resulta el elemento central con el que sentará las bases de su obra posterior. Pagès Jordà escoge así la ironía como vía más idónea para cuestionar las bases y los planteamientos a partir de los cuales se organiza y se relaciona la sociedad moderna actual, en una realidad compleja y, a menudo, como afirma el mismo autor, "prou desagradable" (Serra, Vicenç Pagès Jordà... s.p.). Este objetivo se hace presente en El món d'Horaci a través del conjunto de ironías que hemos analizado: la metaficción irónica, cuyo funcionamiento hace que la novela gire hacia ella misma y plantea una lectura que va más allá de la simple reproducción de la realidad que conocemos; y la ironía verbal (comparaciones, hipérboles) que nos permite observar los usos estereotipados del lenguaje.

\section{BIBLIOGRAFÍA}

Ayats, Andreu. L'aventura de narrar. L'ofici de narrador i els seus moments inefables. Barcelona: Octaedro, 2001.

Alcover, Antoni Maria y Francesc de Borja Moll. Diccionari català-valencià-balear. http:// dcvb.iecat.net. Junio de 2017.

Ballart, Pere. Eironeia. La figuración irónica en el discurso literario moderno. Barcelona: Quaderns Crema, 1994.

Carbó, Ferran. et al. El bricolatge literari. De la paròdia al pastitx en la literatura catalana contemporània. Barcelona: Publicacions de l'Abadia de Montserrat, 2008.

La literatura davant el mirall. Ironia i meta literatura en l'època contemporània. Barcelona: Publicacions de l'Abadia de Montserrat, 2011.

et al. (eds.). La ironia en les literatures occidentals des de l'inici de segle fins a

1939. Barcelona: Publicacions de l'Abadia de Montserrat, 2016.

Genette, Gérard. Figures III. París: Seuil, 1972.

Nouveau discours du récit. París, Seuil, 1983.

Seuils. París: Seuil, 2002 [1987].

Gregori, Soldevila. "Metaficció irònica a Estremida memòria, de Jesús Moncada", Caplletra 41 (2006): 131-150.

Guillamon, Julià. “Aventuras en un piso de estudiantes”, La Vanguardia 19-I (1996): 34.

La ciutat interrompuda: de la contracultura a la Barcelona postolímpica. Barcelona:

La Magrana, 2001. 
Hannoosh, Michele. La Parodie. París: Hachette, 1994.

Hutcheon, Linda. Narcissistic Narrative. The Metafictional Paradox. New York-London: Methuen, 1985 [1980]. 1988.

Juan-Navarro, Santiago. Postmodernismo y metaficción historiográfica: una perspectiva interamericana. València: Departament de Filologia Anglesa i Alemanya de la Universitat de València, 2002.

Marrugat, Jordi. Narrativa catalana de la postmodernitat. Històries, formes i motius. Barcelona: Universitat de Barcelona, 2014.

Muecke, Douglas C. Irony. Londres: Methuen, 1970.

Niogret, Philippe. Les figures de l'ironie dans À la recherche du temps perdu de Marcel Proust. París: L'Harmattan, 2014.

Pagès Jordà, Vicenç. Cercles d'infinites combinacions. Barcelona: Empúries, 1990.

"Vint-i-un anys després. Epíleg de Vicenç Pagès Jordà", Vicenç Pagès Jordà. El món d'Horaci. Barcelona: Empúries, 2016. 389-398.

El món d'Horaci. Barcelona: Empúries, 2016 [1995].

Pons, Pere Antoni. "Paranoies lúdiques des de la Barcelona olímpica". Ara 19-XI (2016): 47.

Puigdevall, Ponç. "Els perseguidors”. El Punt 20-I (1996): s.p.

"Epílegs que insinuen”, El País. Edició Catalunya, 26-XII-2016. http://cat.elpais. com/cat/2016/12/22/cultura/1482403695_101134.html. Junio de 2017.

Samoyault, Tiphaine. L'Intertextualité. Mémoire de la littérature. París: Nathan, 2001.

Schoentjes, Pierre. Poétique de l'ironie. París: Seuil, 2001.

Serra, Màrius. "Encadenats a Horaci”. Avui, 11-I (1996): s. p.

Serra, Montserrat. "Vicenç Pagès Jordà: 'Per mi, l’art és l'organització de la passió"”, Vilaweb, 20-XII (2016). http://www.vilaweb.cat/noticies/vicenc-pages-jorda-a-el-mon-dhoraciconflueixen-la-realitat-la-ficcio-i-el-deliri/. Junio de 2017.

Serrano Valenzuela, Sara. "Vicenç Pagès Jordà", Visat 13 (2012). http://www.visat.cat/ traduccions-literatura-catalana/eng/autor/167/vicenc-pages-jorda.html. Mayo de 2017.

Sullà, Enric. "Un lector opina” Vicenç Pagès Jordà. El món d'Horaci. Barcelona: Empúries, 2016. 399-407.

Waugh, Patricia. Metafiction. The Theory and Practice of Self-Conscious Fiction. 1984. New York: Methuen, 1993. 